\title{
Prevalence of Small Ruminant Trypanosomosis in Dangur District, Metekel Zone, Benishangul Gumuz Region, North Western Ethiopia
}

\author{
Kumela Lelisa ${ }^{1 *}$, Adem Abdela ${ }^{2}$ and Delesa Damena ${ }^{3}$ \\ ${ }^{1}$ National Institute for Control and Eradication of Tsetse Fly and Trypanosomosis, Addis Ababa, Ethiopia \\ ${ }^{2}$ College of Veterinary Medicine, Haramaya University, Dire Dawa, Ethiopia \\ ${ }^{3}$ National Animal Health Diagnostic and Investigation Center, Sebeta, Ethiopia
}

\begin{abstract}
A cross sectional study was conducted in Dangur district, North Western Ethiopia from February to June, 2013 to determine the prevalence of trypanosomosis in small ruminants using dark phase contrast buffy coat examination Blood samples were collected from 312 randomly selected small ruminants including sheep (108) and goats (204) of different sexes and body conditions in five peasant associations. Of the total small ruminants examined during the study period, 8 animals $(2.56 \%)$ were infected with trypanosomes. Out of the total examined, $(3.70 \%)$ four sheep and four $(1.96 \%)$ goats were found infected. Infections were due to Trypanosoma vivax (1.85\%) and Trypanosoma congolense $(0.98 \%)$ in both sheep and goats. There was no statistically significant difference $(P>0.05)$ between season, body conditions, species and sexes on infection rate. The overall Mean Packed Cell Volume (PCV) value of examined animals was $27.66 \%$. The difference in mean PCV of parasitaemic $(23.13 \%)$ and aparasitaemic $(27.78 \%)$ animals was not significant $(P>0.05)$ although, lower mean PCV was recorded in parasitaemic animals. Although, the present study revealed low prevalence $(2.56 \%)$ of trypanosomosis in small ruminants in the study area, the impact of this disease on production, and the role of these small ruminants as potential risk of transmission to other livestock should not be under estimated. Therefore, appropriate intervention measures need to be taken.
\end{abstract}

Keywords: Dangur; North west Ethiopia; Prevalence; Small ruminants; Trypanosomosis

\section{Introduction}

Ethiopia is endowed with huge and diverse livestock population that plays an important role in the economy and livelihoods of farmers and pastoralists. Livestock are a "Living bank" or "Living account" for rural and urban poor farmer, or livestock owners. They serve as a financial reserve for period of economic distress such as crop failure as well as primary cash income. Despite the large population of animal, productivity in Ethiopia is low and even below the average when compared to most countries in Sub-Saharan Africa. This is due to poor nutrition, reproduction insufficiency, management constraints and prevailing animal disease $[1,2]$.

Although, livestock disease has beleaguered farmers worldwide, animal trypanosomosis was particularly detrimental [3,4]. It is a wasting disease in which there is a slow progressive loss of condition accompanied by increasing anemia and weakness to the point of extreme emaciation, collapse and death [5].

In tsetse fly infested areas, animal trypanosomosis is the most important livestock disease caused by variety of species and sub species of the genus Trypanosoma [6]. Six species of trypanosomes have been recorded in Ethiopia and most important trypanosomes in terms of economic loss in livestock are the tsetse transmitted species: Trypanosoma congolense, Trypanosoma vivax and Trypanosom brucei affecting cattle, sheep and goats [7]. Trypanosomosis is prevalent in two main regions of Ethiopia that is, the north-west and the southwest regions [8]. In these regions, tsetse fly transmitted animal trypanosomosis is a major constraint to utilization of the large land resources.

Tsetse flies (Glossina species) are the principal vectors of trypanosomosis in Sub-Saharan Africa. Other blood sucking flies such as Stomoxys, Haematopota and Tabanus species may also transmit the disease. Wild animal such as bush pigs, bush bucks, kudus, warthogs and buffaloes act as reservoir of infection in endemic areas. The influence of tsetse fly on Africa agriculture through the transmission of trypanosomosis continues to be a major constraint to the development of national economy, and their achievement of self-sufficiency in basic food production [9].

In Ethiopia, the tsetse flies are confined to the southern, southwestern and north-western regions where there are five species of tsetse fly (Glossina): namely G. morsitans submorsitans, G. pallidipes, G. f. fuscipes, G. tachnoids and G. longipennis. Among these species the first four are widespread and most important while, G. longipennis is of minor economic importance [10,11]. Little is known about the prevalence of trypanosome infections in sheep and goats in the study area. Therefore, this study was carried out to determine the prevalence of trypanosomosis in small ruminants in Dangur district, Metekel zone, Benishangul Gumuz Region, North Western Ethiopia.

\section{Materials and Methods}

\section{Study area}

Dangur district is located in Metekel zone of Benishangul Gumuz regional state. It is situated at $563 \mathrm{~km}$ North-west Addis Ababa. The district has 837,700 ha of land. The agro- climate of the area alternates

*Corresponding author: Kumela Lelisa, National Institute for Control and Eradication of Tsetse Fly and Trypanosomosis, PO Box 19917, Addis Ababa Ethiopia, Tel: +251912912079; E-mail: lelisakumela@gmail.com

Received March 19, 2016; Accepted May 10, 2016; Published May 16, 2016

Citation: Lelisa K, Abdela A, Damena D (2016) Prevalence of Small Ruminant Trypanosomosis in Dangur District, Metekel Zone, Benishangul Gumuz Region North Western Ethiopia. J Vet Sci Technol 7: 334. doi:10.4172/2157-7579.1000334

Copyright: ( 2016 Lelisa K, et al. This is an open-access article distributed under the terms of the Creative Commons Attribution License, which permits unrestricted use, distribution, and reproduction in any medium, provided the original author and source are credited. 
with long summer rainfall (June to September) and winter dry season (December to March). The mean annual rainfall in the district ranges from 900 to $1400 \mathrm{~mm}$. The annual temperature in Dangur district ranges from 30 to $38^{\circ} \mathrm{C}$. The district is located in Blue Nile valley. The main rivers in Dangur district include: Beles and Ayma with many other tributaries that enter these rivers, including Hypapo, Manbuk, Anja, Anzibuka, kokel and Gublak. The distribution of tsetse fly is associated with the presence or absence of large game animals, which serve as sources of food for the tsetse fly. The area has got a number of wild animals which include African buffaloes, bush pigs, warthog, bush buck, lion, kudu, hippopotamus, crocodiles, hyena, velvet monkey and antelopes, many of which serve as reservoir of infection for trypanosomes.

\section{Sample size and sampling method}

The sample size was determined with $50 \%$ expected prevalence to increase the precision of the data using the formula described by Ref. [12].

$$
\begin{aligned}
& N=\frac{1.96^{2}\left(\mathrm{P}_{\exp }\left(1-\mathrm{P}_{\exp }\right)\right)}{d^{2}} \\
& \text { Where, N: The sample size } \\
& \text { d: The desired absolute precision } \\
& \text { P: The expected prevalence }
\end{aligned}
$$

\section{d: The desired absolute precision \\ P: The expected prevalence}

Accordingly, a total of 312 small ruminants were randomly sampled from five peasant associations to determine the prevalence of trypanosomosis in these small ruminants.

\section{Study population}

This study was carried on 108 local sheep and 204 goats selected using random sampling methods in the five peasant associations. Information obtained was on the sex, species, and body condition of the small ruminants, while packed cell volume was determined from collected blood samples. The body condition scoring of animals was based on Ref. [13].

\section{Parasitological study}

Blood samples were collected from the ear vein of sheep and goats after puncturing of the ear vein using lancet. The blood was channeled into a heparanized micro haematocrit tubes and then one end of the tube was sealed by crystal sealant and spun at 12,000 rpm for five minutes to separate the blood cells and to concentrate trypanosomes using centrifugal force as buffy coat. The PCV of each sample was recorded. Then the sample was examined under microscope using Buffy Coat technique. The trypanosome species were identified by observing under the microscope from Giemsa stained thin blood films [14].

\section{Data analysis}

Data obtained on individual animals and parasitological examination results were entered into Microsoft Excel program 2007, and later on analyzed with statistical package for the social sciences (SPSS) version 20 statistical software program. The prevalence of trypanosomes infection was calculated as the number of parasitological positive animals as examined by the Buffy coat method divided by the total number of animals investigated at that particular time and multiplied by 100 . The association between the prevalence of trypanosome infection and risk factors were assessed using Chi-square test, whereas the student's $t$-test was used to assess the difference in mean PCV between trypanosome positive and negative animals. The test result was considered significant when the calculated $p$-value was less than 0.05 .

\section{Results}

\section{Parasitological findings}

The overall prevalence of trypanosomosis in small ruminant in the study area was $2.56 \%$. Out of the total examined sheep (108), 4 were infected with trypanosomes while 4 goats were infected out of 204 goats examined. The prevalence of trypanosomosis in sheep and goats was 3.70 and $1.96 \%$, respectively. The difference in the trypanosome prevalence between the two species was not statistically significant $(\mathrm{P}>0.05)$ (Table 1). Half $(50 \%)$ of the parasitaemic animals were infected with $T$. congolense, and the rest were infected with T. vivax. Therefore, both Trypanosoma species were responsible for infection of sheep and goats in the study area. The prevalence on the basis of season was 3.01 and $2.05 \%$ in dry and rainy season, respectively. As to the infection rate between the two sex groups, an infection rate of 0.96 and $1.60 \%$ was recorded for male and female animals, respectively. There was no significance difference in the prevalence of trypanosomosis between the two sexes $(\mathrm{P}>0.05)$. The prevalence of trypanosomes among animals with poor, good and medium body condition was $7.69,2.5$ and $1.55 \%$, respectively. The difference in prevalence among these three groups was not statistically significant $(\mathrm{P}>0.05)$.

\section{Hematological findings}

The overall mean PCV value of examined animals was $27.66 \%$. The mean PCV values of parasitemic and aparasitemic animals were 23.13 and $27.78 \%$ respectively. The mean PCV value of sheep and goats were 28.59 and $27.17 \%$ respectively. The mean PCV in dry and rainy season were 27.99 and $27.29 \%$ respectively; while the mean PCV for male and female animals were 28.94 and $27.42 \%$, respectively. Mean values of PCV, on the basis of body condition score were 25.44, 28.21, and 27.88\% in poor, good and medium body conditioned animals, respectively.

\section{Discussion}

The overall prevalence of trypanosomosis in small ruminants recorded in the study area was $2.56 \%$. Similar values $(2.11 \%)$ were also reported by Tadese and Megersa [15] in small ruminants in Guto Gida district, Western Ethiopia. Samdi et al. [16] reported a prevalence of $2.10 \%$ at Kaduna abattoir, Nigeria. The present finding is lower to what was reported from other parts of Ethiopia by Mekonnen et al. [17] who

\begin{tabular}{|c|c|c|c|c|}
\hline Variable & No. of examined (\%) & No. of positive (\%) & P-value & $x^{2}$ \\
\hline \multicolumn{5}{|l|}{ Sex } \\
\hline Male & $50(16.03)$ & $3(37.5)$ & 0.12 & 2.81 \\
\hline Female & $262(83.97)$ & $5(62.5)$ & & \\
\hline \multicolumn{5}{|c|}{ Body condition } \\
\hline Poor & $39(12.5)$ & $3(37.5)$ & & \\
\hline Medium & $193(61.86)$ & $3(37.5)$ & 0.09 & 4.89 \\
\hline Good & $80(25.64)$ & $2(25)$ & & \\
\hline \multicolumn{5}{|l|}{ Species } \\
\hline Caprine & $204(65.38)$ & $4(50)$ & & \\
\hline Ovine & $108(34.62)$ & $4(50)$ & 0.28 & 0.86 \\
\hline \multicolumn{5}{|l|}{ Season } \\
\hline Dry & $166(53.21)$ & $5(62.50)$ & 0.43 & 0.29 \\
\hline Rainy & $146(46.79)$ & $3(37.50)$ & & \\
\hline
\end{tabular}
reported $10.57 \%$ prevalence in goats in Abelti, Bede and Ghibe valley,

Table 1: Prevalence of trypanosomosis and associated risk factors in smal ruminants. 
South-west Ethiopia. Dinka and Abebe [18] also reported a prevalence of 5.1\% in Didessa and Ghibe Valley, south-west Ethiopia while Kebede et al. [19] reported 5.6\% prevalence in Guangua district of northwestern Ethiopia. The lower prevalence of trypanosomosis recorded in small ruminants in this study may be attributed to the practice of application of control measures such as spray of animals with acaricides and regular treatment of sick animals. The present value was relatively higher than the reports of Lemecha et al. [20] who reported 2.0 and $0.4 \%$ in sheep and goats respectively; while Kalu and Uzoigwe [21] observed a prevalence of $1.2 \%$ in sheep and $0.7 \%$ in goats. Ohaeri [22] had earlier reported $1.2 \%$ of trypanosomosis prevalence in goats and $1.1 \%$ in sheep in Abia, Nigeria. The higher prevalence of trypanosomosis could be due to differences in epidemiological factors.

Prevalence of infection among the infected animals indicated lower infection rate in goats (1.96\%) than in sheep (3.70\%). The higher prevalence in sheep than goats was also reported by Lemecha et al. [20] who reported 2.0 and $0.4 \%$ in sheep and goats, respectively; Kalu and Uzoigwe [21], observed a prevalence of 1.2 in sheep and $0.7 \%$ in goats; Bacha et al. [23] reported $3.6 \%$ in sheep and $3.17 \%$ in goats, and Ohaeri [22] reported $1.2 \%$ in goats and $1.1 \%$ in sheep in parts of Abia, Nigeria. However, the values for sheep and goats as reported in this study were lower than the findings of Dinka and Abebe [12] who reported $7.6 \%$ in sheep and 3.6\% in goats. Several authors have shown that the prevalence was lower in goats than in sheep because of differences in susceptibility to infection between goat and sheep. This is usually related to tsetse feeding that means the anti-feeding behavior of goats and the docile nature and wool cover of the sheep [24,25].

Two species of trypanosomes, namely $T$. vivax and T. congolense were identified in the study area during the study period. Similar findings were also reported by Tadesse and Megersa [15] who concluded that $T$. congolense and T. vivax were the two trypanosomes which pose major threats to sheep and goats in Western Ethiopia.

Although, the difference in prevalence between dry and rainy seasons was not statistically significant $(\mathrm{P}>0.05)$, the current finding indicated higher prevalence in dry season than rainy season. This result is inconsistent with the report of Ameen et al. [26] in Ogbomoso Area of Oyo State, Nigeria. With regard to the infection rate among animals with different body condition scores, the highest prevalence of trypanosome infection was observed in animal of poor body condition which was followed by medium then good body condition. This indicates that trypanosomosis may be responsible for emaciation in animals thereby leading to poor body condition, although, there are also animals with poor body condition which are parasitologically negative.

The PCV value was calculated having considered $(22-45 \%)$ as normal PCV for sheep and (22-38\%) for goats. The difference in the mean PCV value of infected (23.13\%) small ruminant was not statistically significant $(\mathrm{P}>0.05)$ from those of the non-infected (27.78\%). This indicated that PCV value alone could not be used as diagnostic criterion for trypanosomosis because there are also other factors such as worm infestation and nutritional deficiency which may cause anemia [27]. Other diseases considered to be affecting the PCV values in animals include helmenthiasis and, tick borne diseases $[28,29]$. On the other hand, most of the parasitaemic animals in the low land areas were in good body condition despite having low PCV values. This could be attributed to the fact that animals in low altitude are always in good plane of nutrition due to availability of sufficient pasture [30].

\section{Conclusion}

The present study showed a relatively low prevalence of small ruminant trypanosomosis. However, this is an evidence not to be neglected that trypanosomosis has yet continued to pose a considerable threat to sheep and goats of the study area warranting attention to control this disease to in order to safeguard small ruminants' production.

\section{References}

1. Taddese A, Damene E, Kebede E, Birehanu T, Dabessa G, et al. (2012) Prevalence of Bovine Trypanosomosis and its Vector Density in Daramallo District, South Western Ethiopia. J Vet Adv 2: 266-272.

2. Bekele J, Asmare K, Abebe G, Ayelet G, Gelaye E (2010) Evaluation of Deltamethrin applications in the control of tsetse and trypanosomosis in the southern rift valley areas of Ethiopia. Vet Parasitol 168: 177-184.

3. Alsan M (2012) The effect of the Tsetse fly on African development. National Bureau of Economic Research. 105 Massachusetts, Avenue, Suite 418, Cambridge, MA 02138, USA.

4. Bal MS, Sharma A, Ashuma, Batth BK, Kaur P, et al. (2014) Detection and management of latent infection of Trypanosoma evansi in a cattle herd. Indian J Anim Res 48: 31-37.

5. Uilenberg G (1998) A field guide for diagnosis, treatment and prevention of African animal Trypanosomosis. Adapted from the original edition by Boyt WP. Food and Agriculture Organization of the United Nations (FAO), Rome.

6. Swallow BM (2000) Impacts of trypanosomosis in African agriculture. PAAT technical and scientific series No. 2, FAO, Rome.

7. Abebe G, Jobre $Y$ (1996) Trypanosomosis: a threat to cattle production in Ethiopia. Rev Vet Med 147: 897-902.

8. Abebe G, Korme T, Habtewold D, Keno M (2004) Ethiopian Science and Technology Commission (ESTC), Southern Tsetse Eradication Project (STEP), Midterm Review Report.

9. Food and Agriculture Organization (1992) Training manual for tsetse contro personnel: Use of attractive devices for tsetse survey and control. Food and Agricultural Organization of United Nations, Rome.

10. Abebe G (2005) Trypanosomosis in Ethiopia. Ethiop J Biol Sci 4: 75-121.

11. Keno M (2005) The current situation of tsetse and trypanomosis in Ethiopia Ministry of Agriculture and Rural Development, Veterinary service department in proceeding of 28th meeting of International Scientific Council for Trypanosomosis Research and Control (ISCTRC).

12. Thrusfield M (2007) Veterinary Epidemiology. 3rd edn. Black well science. Oxford, pp: 233.

13. Thompson J, Meyer H (1994) Body condition scoring of sheep, Oregon State University Extension Service offers educational programs.

14. Murray M, Murray PK, Mclntyre WI (1977) An improved parasitological technique for the diagnosis of African trypanosomiasis. Trans R Soc Trop Med Hyg 71: 325-326.

15. Tadesse A, Megerssa G (2010) Prevalence of trypanosomosis in small ruminants of Guto Gidda district, East Wollega zone, Western Ethiopia. Ethiop Vet J 14: 67-77.

16. Samdi S, Abenga JN, Fajinmi A, Kalgo A, Idowu T, et al. (2008) Seasonal Variation in Trypanosomosis Rates in Small Ruminants at the Kaduna Abattoir Nigeria. AJBR 11: 229-232

17. Mekonnen B, Regasa F, Kahsay AG (2014) Epidemiology of trypanosomosis in goats at Abelti, Bede and Ghibe valley South-West Ethiopia. Int J Trop Med 9: 10-14.

18. Dinka H, Abebe G (2005) Small ruminants trypanosomosis in southwest of Ethiopia. Small Rumin Res 57: 239-243.

19. Kebede N, Fetene T, Animut A (2009) Prevalence of Trypanosomosis of small ruminants in Guangua district of Awi Zone, northwestern Ethiopia. J Infect Dev Ctries 3: 245-246.

20. Lemecha H, Hussein I, Lidetu D (2002) Prevalence and Distribution of majo Vector born parasite Infections in Domestic Ruminants and Equine in Ethiopia. National animal health diagnostic center, Sebeta, Ethiopia. 
Citation: Lelisa K, Abdela A, Damena D (2016) Prevalence of Small Ruminant Trypanosomosis in Dangur District, Metekel Zone, Benishangul Gumuz Region, North Western Ethiopia. J Vet Sci Technol 7: 334. doi:10.4172/2157-7579.1000334

Page 4 of 4

21. Kalu AU, Uzoigwe NR (1996) Tsetse fly and trap on the Jos plateau. Observation on out breaks in B/Ladi L.G. Act Trop 14: 114-126.

22. Ohaeri CC (2010) Prevalence of trypanosomosis in ruminants in parts of Abia State, Nigeria. J Anim Vet Adv 9: 2422-2426.

23. Bacha B, Beyene Z, Woyessa M, Hunde A (2013) Prevalence of Small Ruminants Trypanosomosis in Assosa District of Benishalgul Gumuz Regional State, Western Part of Ethiopia. Acta Parasitol Glob 4: 99-104.

24. Bealby KA, Connor RJ, Rowlands GJ (1996) Trypanosomosis of goats in Zambia. ILRI, Nairobi, Kenya.

25. Snow WF, Wacher TJ, Rawlings P (1996) Observations on the prevalence of trypanosomosis in small ruminants, equines and cattle, in relation to tsetse challenge, in The Gambia. Vet Parasitol 66: 1-11.

26. Ameen SA, Joshua RA, Adedeji OS, Raheem AK, Akingbade AA, et al. (2008)
Preliminary Studies on Prevalence of Ruminant Trypanosomosis in Ogbomoso Area of Oyo State, Nigeria. Middle-East J Sci Res 3: 214-218.

27. Radostitis DM, Gray CC, Blood DC, Arundel JH (2000) Veterinary Medicine A textbook of the Diseases of cattle, sheep, pigs, goat and horses, 9th edn Baillière Tindall, London, pp: 1329-1337.

28. Sharma A, Das Singla L, Tuli A, Kaur P, Bal MS (2015) Detection and assessment of risk factors associated with natural concurrent infection of Trypanosoma evansi and Anaplasma marginale in dairy animals by duplex PCR in eastern Punjab. Trop Anim Health Prod 47: 251-257.

29. Sharma A, Singla LD, Ashuma, Bath BK, Kaur P (2016) Clinicopathobiochemical alterations associated with subclinical babesiosis in dairy animals. J Arthropod Borne Dis 10: 259-267.

30. Dagnachew S, Sangwan AK, Abebe G (2004) Epidemiology of bovine trypanosomosis in the Abay Basin Areas of Northwestern Ethiopia. Revue Élev Méd vét Pays trop 58: 151-157. 